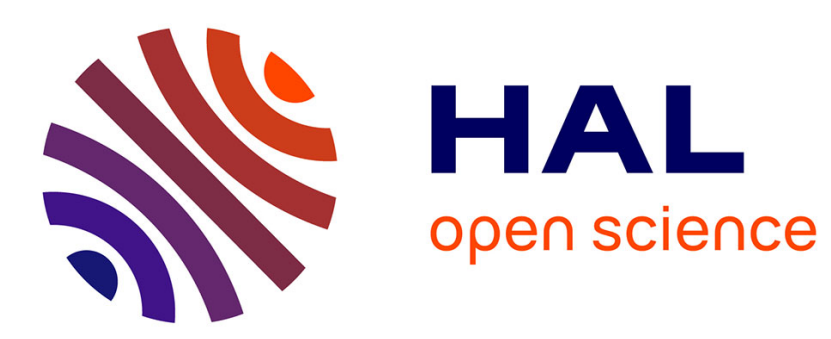

\title{
Epigenetic control by plant polycomb proteins: new perspectives and emerging roles in stress response
}

Filomena de Lucia, Valerie Gaudin

\section{To cite this version:}

Filomena de Lucia, Valerie Gaudin. Epigenetic control by plant polycomb proteins: new perspectives and emerging roles in stress response. From Plant Genomics to Plant Biotechnology, Woodhead Publishing, 2013, 978-1-907568-29-9. 10.1533/9781908818478.31 . hal-01204078

\section{HAL Id: hal-01204078 \\ https://hal.science/hal-01204078}

Submitted on 6 Jun 2020

HAL is a multi-disciplinary open access archive for the deposit and dissemination of scientific research documents, whether they are published or not. The documents may come from teaching and research institutions in France or abroad, or from public or private research centers.
L'archive ouverte pluridisciplinaire HAL, est destinée au dépôt et à la diffusion de documents scientifiques de niveau recherche, publiés ou non, émanant des établissements d'enseignement et de recherche français ou étrangers, des laboratoires publics ou privés. 
Epigenetic control by plant Polycomb proteins: new perspectives and emerging roles in stress response

\author{
Filomena De Lucia, Institut Pasteur, France, \\ and Valérie Gaudin, Institut Jean-Pierre \\ Bourgin, France
}

DOI: $10.1533 / 9781908818478.31$

Abstract: In eukaryotes, cell-fate determination, differentiation and developmental programs require precise spatial and temporal control of gene expression. Polycomb group ( $\mathrm{PcG}$ ) proteins are key transcriptional regulators in these mechanisms. Research over the past decade has demonstrated the significance of the Polycomb system in establishing silent chromatin states and perpetuating them through cell divisions. PcG mediated gene silencing is a fundamental and conserved mechanism employed by both plants and animals. In plants these proteins maintain cell identity and imprinting and control important developmental transitions, hence having agronomical impacts.

In this chapter, we discuss the impact of Polycomb regulation in controlling epigenetic states in plants. We highlight recent reports about the role of long non-coding RNAs as PcG cofactors and the involvement of PcG complexes in stress responses. Indeed, how plants respond to environmental stresses by modifying expression of the genome is a challenge in plant biology, and unexplored links between stress response and PcG regulation are promising.

Key words: Polycomb group (PcG) proteins, Polycomb responsive element (PRE), Polycomb repressive complex (PRC), chromatin, long non-coding RNAs, histone modification, histone marks. 


\subsection{Introduction}

Polycomb group $(\mathrm{PcG})$ proteins are key chromatin regulators present in both plants and animals. They work as multi-protein complexes, cooperatively establish silent chromatin states and are involved in the transmission of epigenetic states. Despite the recent progress in both animal and plant fields, PcG mechanisms of action are still poorly understood, impeding the progress towards a full understanding of eukaryote development. How these key chromatin complexes are recruited to specific target genes still remains one of the major questions. Two important achievements in the field have recently had a profound impact on the understanding of the mechanism of action of the Polycomb system and the regulation of PcG target genes: (i) the discovery of noncoding RNAs (ncRNAs) interacting with PcG prôteins (Spitale et al., 2011; Wang and Chang, 2011) and (ii) the interplay between nuclear organization and PcG mediated gene regulation (Bantignies and Cavalli, 2011).

In the plant model Arabidopsis thaliana, PcG complexes have been extensively characterized in relation to plant development (for reviews see Butenko and Ohad, 2011, Holec and Berger, 2012; Köhler and Hennig, 2010), but they have only recently been reported to play a role in perenniality and stress responses. Here, we focus on these questions and we will integrate the current knowledge in the field at the interface with plant responses under stress conditions.

\subsection{Conserved multi-protein complexes with histone post-translational modifying activities}

Studies in Drosophila melanogaster described at least three main types of complexes with different functions which serve as reference types in both animal and plant species: Polycomb repressive complex 1 (PRC1), PRC2, and the Pleiohomeotic repressive complex (Pho-RC) (reviewed in Margueron and Reinberg, 2011; Schuettengruber and Cavalli, 2009; Simon and Kingston, 2009). Pho-RC contains Pleiohomeotic (Pho), a sequence-specific DNA-binding protein, and the Smc-related protein containing four MBT domains (Sfmbt). This complex remains to be described in plants. While no enzymatic activity has been associated with the Pho-RC complex, the two PRC complexes have histone tail 
post-translational modifying activities. PRC2 catalyses the trimethylation of the histone $\mathrm{H} 3$ lysine 27 residue $(\mathrm{H} 3 \mathrm{~K} 27 \mathrm{me} 3)$ at target loci, while PRC1 can recognize $\mathrm{H} 3 \mathrm{~K} 27 \mathrm{me} 3$ and establish $\mathrm{H} 2 \mathrm{~A}$ histone monoubiquitination. Thus, PRC1 functions downstream of PRC2 to maintain the repressive state and mediate gene expression control in various biological processes. However, besides the current hierarchical model, which posits two sequential steps by PRC2 and PRC1, respectively, recent studies in animals suggest that $\mathrm{H} 3 \mathrm{~K} 27 \mathrm{me} 3$ is not always sufficient or required as a docking site for PRC1 recruitment, and that PRC1 may act in a PRC2-independent manner (Gao et al., 2012; Simon and Kingston, 2009; Sing et al., 2009; Tavares et al., 2012). Besides its catalytic activity, PRC1 also has chromatin compaction activity which can be independent of monoubiquitination; however both activities impact gene expression regulation (Endoh et al., 2012; Eskeland et al., 2010).

A PRC2-type complex is composed of four-subunits, among which Enhancer of Zeste $(\mathrm{E}(\mathrm{Z}))$ is a SET ( $\underline{\mathrm{S}} \mathrm{u}(\mathrm{var})-\mathrm{E}(\mathrm{z})$-Thritorax) domain protein that possesses $\mathrm{H} 3 \mathrm{~K} 27$ histone methyltransferase (HMT) activity. The $E(Z)$ protein on its own has a null or low activity and requires noncatalytic subunits. The other subunits are Suppressor of Zeste 12 $(\mathrm{Su}(\mathrm{Z}) 12)$, the nucleosome remodelling p55 factor and Extra sex combs (Esc/EED) (Figure 3.1).

$\mathrm{Su}(\mathrm{Z}) 12$ is a protein containing a $\mathrm{C} 2 \mathrm{H} 2$ zinc-finger domain and VEFS, a conserved domain among plant and drosophila homologs (VRN2-

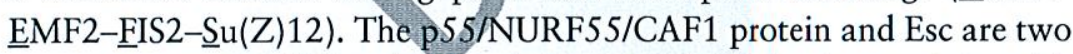
WD 40 proteins, the former being involved in interaction with
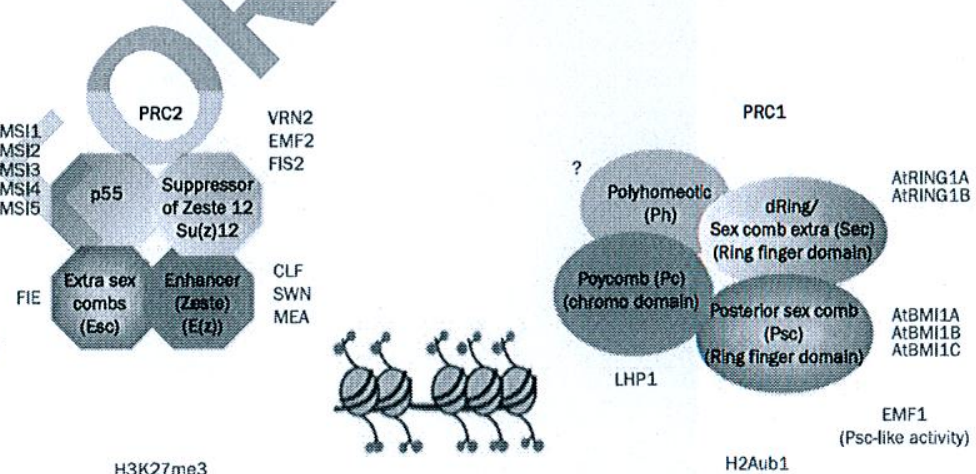

Figure 3.1

Core components of the PRC complexes in Drosophila and $A$. thaliana. PRC2 deposits the H3K27me3 silent epigenetic mark whereas $\mathrm{H} 2 \mathrm{~A}$ monoubiquitination is achieved by PRC1 
nucleosomes and the latter able to modulate the HMT activity. Besides the four core subunits, regulatory subunits (PcG cofactors) have been described in animals that can associate with the PRC2 complex and influence its function, such as Polycomb like (PCL) or JARID2, a histone demethylase essential for developmental control despite impaired enzymatic activity (Landeira and Fisher, 2011).

In A. thaliana, extensive genetic analysis of the PcG proteins has been conducted, revealing that PRC2 is structurally conserved and comprises homologs of the four core subunits (reviewed in Köhler and Hennig, 2010). One of the PRC2 core subunits, the Extra sex combs (Esc) homolog, is encoded by a unique gene, FERTILIZATIONINDEPENDENT ENDOSPERM (FIE), whereas the three other PRC2 core subunits are encoded by small gene families up to five members. The MULTICOPY SUPPRESSOR OF IRA 1 to 5 genes (MSI1-5) entcode the PRC2 p55 homolog, whereas EMBRYONIC FLOWER2 (EMF2), FERTILIZATION INDEPENDENT SEED2 (FIS2) and VERNALIZATION2 (VRN2) are the homologs of the drosophila $\mathrm{Su}(\mathrm{Z}) 12$ protein. CURLY LEAF (CLF), SWINGER (SWN, also known as EZA1), and MEDEA (MEA) are the homologs of the $\mathrm{E}(\mathrm{Z}) \mathrm{PRC} 2$ histone methyltransferase. The three $\mathrm{E}(\mathrm{Z})$ HMTs differ by their expression patterns throughout the plant life cycle. $M E A$ is expressed predominantly in the female gametophyte and developing seeds but not in mature seeds and seedlings, whereas CLF and $S W N$ are present in vegetative tissues. Redundancy issues are certainly responsible for the difficulty of an unambiguous identification of complex composition, and as yet scant biochemical data exist on the characterization of the specific complexes. Three main PRC2 complexes have been characterized (Hennig and Derkacheva, 2009; Köhler and Hennig, 2010) and associated with different plant developmental stages (the EMBRYOONIC FLOWER (EMF), VERNALIZATION (VRN) and FERTIUIZATION INDEPENDENT SEED (FIS) complexes). PcG cofactors similar to PCL have been described in plants. The H3K27 trimethylation activity of the VRN-PRC2 complex is increased by the interaction with three related plant homeodomain (PHD) finger proteins, VEL1, VRN5 and VIN3, that form the PHD-PCR2 complex involved in the vernalization process (De Lucia et al., 2008) (Figure 3.2).

While PRC2 complexes are evolutionarily conserved, PRC1 complexes are more plastic and heterogeneous in eukaryotes, suggesting that they form a small family (Schuettengruber and Cavalli, 2009). The four core components of the drosophila PRC1 complex are: Polycomb (Pc), a protein whose chromodomain recognizes the silencing mark H3K27me3, Polyhomeotic $(\mathrm{Ph})$ (a protein containing SAM and C2-C2 zinc finger 


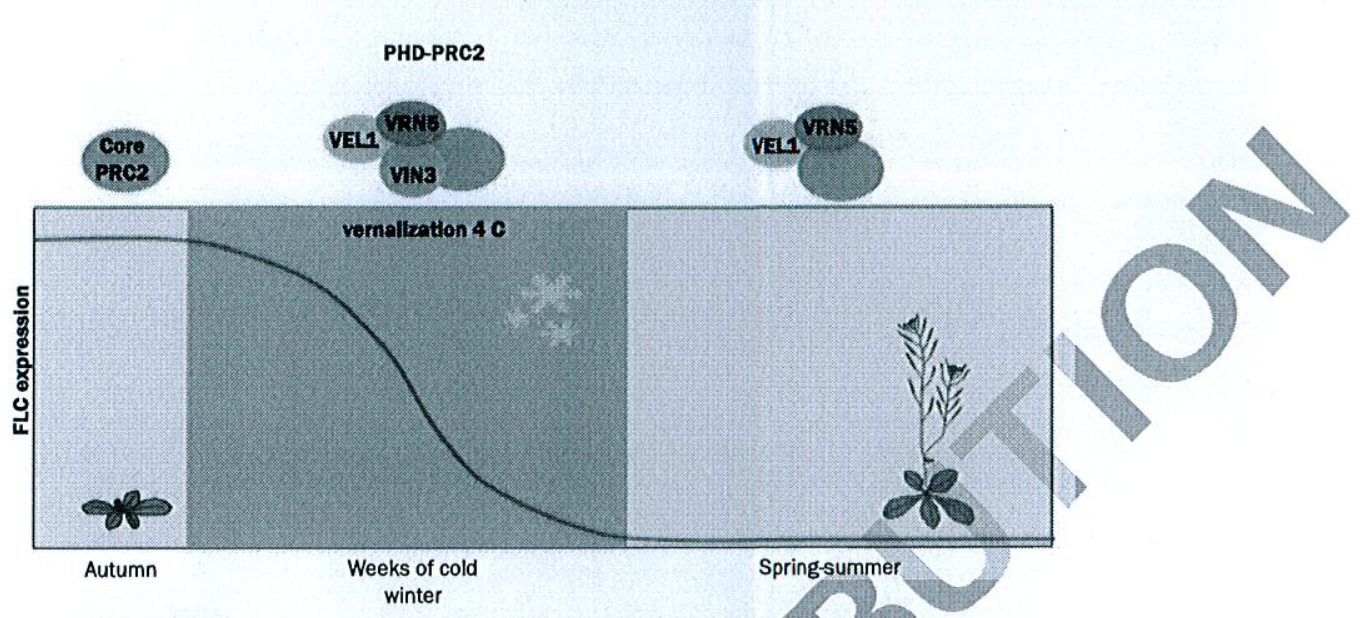

Figure 3.2 The vernalization process and the PRC2 complexes

domains), and two PRC1 RING proteins, drosophila Ring finger protein 1/Sex combs extra (dRing/Sce) and Posterior sex combs (Psc).

The PRC1 RING proteins contain a Ring-finger domain at the $\mathrm{N}$-terminal region and the RAWUL (Ring-finger and WD40 associated Ubiquitin-Like) domain at the C-terminal region, and they are further subdivided into RING subfamily (dRing/RING1A/RING1B) and BMI subfamily (Psc/Polycomb group RING fingers (PCGFs)/BMI proteins) (Sanchez-Pulido et al., 2008).

Some of the PRC1 subunits are encoded by small families in mammals and plants, giving rise to a diversity of PRC1 complexes (Figure 3.1). In an extensive proteomic study, six mammalian PRC1 complexes have been reported, corresponding to combinatorial associations of the different PcG homologs, all of which contain RING1A/B and are distinguishable by their Psc homologs (PCGF1 to 6) (Gao et al., 2012). By analysing the genomic localization of different subunits of the six PRC1 complexes, regions bound exclusively or predominantly by one of the six PCGF were identified, highlighting that the different complexes have distinct genomic localizations (Gao et al., 2012). Additional components are also found associated with PRC1 in substoichiometric amounts, such as the PcG protein Sex Comb on Midleg $(\mathrm{Scm})$, and an atypical PRC1 complex, dRING associated Factors (dRAF), comprising dRING, Psc, and the H3K36me2 histone demethylase KDM2 has been reported (Lagarou et al., 2008). Interestingly, the Psc subunit is crucial for inheritance of chromatin features throughout DNA replication (Lo et al., 2012). 
In plants, recent data indicate that the chromodomain protein LIKE HETEROCHROMATIN PROTEIN1 (LHP1) (Gaudin et al., 2001) and homologs of the two drosophila RING-finger domain proteins form a complex similar in domain composition and function to animal PRC1 (Bratzel et al., 2010; Chen et al., 2010; Xu and Shen, 2008; Zhang et al., 2007b). The chromodomain of LHP1 binds to trimethylated lysines H3K27 and H3K9me3 in vitro (Zhang et al., 2007b). However, LHP1 is mainly localized in euchromatin in vivo (Libault et al., 2005), and its genome-wide distribution indicated that LHP1 mainly co-localizes with $\mathrm{H} 3 \mathrm{~K} 27 \mathrm{me} 3$ in vivo, suggesting that LHP1 is a functional homolog of Pc (Turck et al., 2007; Zhang et al., 2007b). Recent works have identified 5 RING-finger domain proteins interacting with LHP1, AtRING1A/B and AtBMI1A/B/C, AtBMI1A/B having a $\mathrm{H} 2 \mathrm{~A}$ monoubiquitination activity (Bratzel et al., 2010; Chen et al., 2010; Xu and Shen, 2008). The plant-specific EMF1 protein interacts physically with some of the plant PRC1 subunits, thus participating in a PRC1-like complex (Calonje et al., 2008). Recently, EMF1 was shown to bind tightly to free DNA and to inhibit chromatin remodeling, having a Psc-like activity (Beh et al., 2012). Beside the chromodomain, LHP1 possesses a chromoshadow domain with protein-protein interaction properties (Gaudin et al., 2001). Consistently, several LHP1 partners have been found, such as transcription factors (SCARECROW (Cui and Benfey, 2009) and SHORT VEGETATIVE PHASE (SVP) (Liu et al., 2009)), as well as various chromatin-associated proteins (del Olmo et al., 2010; Li and Luan, 2011; Gaudin, unpublished data). These associated proteins, such as transcription factors, could participate in specifying sets of PcG target genes, as already reported in animals (Yu et al., 2012), giving rise to PRC1 variant complexes, or modulating the plant PRC1 activity.

In the coming years, we expect a rapid evolution of the biochemical complexity of the plant PRC complexes by the identification of homologous proteins or additional regulatory partners, to fulfil the diverse functions of these complexes in planta. The diversity of the complexes may also be accompanied by variations in the recruitment pathways (histone marks, Polycomb-response elements (PREs), transcription factors, RNA cofactors ...) as well as transcription repression mechanisms (direct interference with the transcription machinery (Lehmann et al., 2012), modulation of chromatin compaction, inhibition of chromatin remodelling, effects on higher-order nuclear structures). 


\subsection{Polycomb functions in plant development}

Plants, which evolved multicellularity independently of animals, utilize the PcG system in strikingly similar ways (Meyerowitz, 2002). The developmental functions of the plant PcG are evident from the multitude of developmental defects exhibited by mutants of various PcG subunit genes (Bratzel et al., 2010; Gaudin et al., 2001; Goodrich et al., 1997; Grossniklaus et al., 1998; Hennig et al., 2003; Luo et al., 1999; Ohad et al., 1999; Xu and Shen, 2008), indicating that PcG complexes play a crucial role in all major stages of plant development and progressions through the plant life cycle. A complete loss of PcG function in plant cells inhibits cell differentiation and activates an embryo-like state (Bratzel et al., 2010; Chanvivattana et al., 2004; Chen et al., 2010), suggesting that PcG is required to control cell identity and the ability to form different tissues with diverse functions. PcG function is also required to maintain gametophytic identity of cells (for review see Köhler and Hennig, 2010). Moreover, the system controls one of the most important developmental transitions plants make, the floral transition, from vegetative growth to reproductive flowers. The PcG system regulates flowering through a process called vernalization that allows plants to flower after long periods of cold in more favourable conditions in spring (Kim et al., 2009). This is achieved via down-regulation of FLOWERING LOCUS C (FLC), whose repression is maintained by the Polycomb system (Bastow et al., 2004; De Lucia et al., 2008; Gendall et al., 2001; Greb et al., 2007; Mylne et al., 2006); for review see Kim and Sung (2012) (Figure 3.2).

With the identification of PcG targets at the genomic scale via the analysis of the trimethylated H3K27, signature of Polycomb repression, and the in-depth studies on a few PcG targets in plants, the crucial role of the PcG in plant development is highly appreciated. In A. thaliana, H3K27me3 is found at approximately $20 \%$ of annotated genes (Zhang et al., 2007a), essentially transcriptional regulators but also genes encoding microRNAs, and fluctuates according to tissues and developmental stages, thus allowing fine-tuning of gene expression during plant differentiation (Lafos et al., 2011). The genome-wide distribution of the PRC1 subunit LHP1 by DamID approach (Germann and Gaudin, 2011) identified about 2300 target regions and 4000 genes distributed over the five chromosomes, of which $90 \%$ are associated with H3K27me3 (Zhang et al., 2007). These 
data confirm the hierarchical mechanism of PRC complexes, but also suggest that PRC1 might act independently of PRC2 for a tiny set of target regions devoid of H3K27me3 (Zhang et al., 2007b).

\subsection{Non-coding RNAs as regulatory cofactors of Polycomb complexes}

Recent high throughput sequencing approaches have listed thousands of non-coding RNAs (ncRNAs) in mammals with an extraordinary diversity, these molecules being transcribed either from intergenic regions or from intragenic regions in sense or in antisense orientation. As their functionalities were questioned, the last few years saw mounting evidence of regulatory roles of ncRNAs, ranging from 50 to several $\mathrm{kbp}$ in length, as signals, decoys, guides and/or scaffolds in assembling and regulating various protein complexes and thus impacting gene expression (Wang and Chang, 2011). In particular, their association with chromatin-modifying enzymes and PRC2 complexes has been recently reported (for reviews see Bracken and Helin, 2009; De Lucia and Dean, 2011; Guttman and Rinn, 2012; Nagano and Fraser, 2011). This emerging theme already has many examples in the animal fields. The pioneer HOTAIR IncRNA regulating the HOX-D locus (Rinn et al., 2007; Tsai et al., 2010), the RepA/Xist RNA involved in X chromosome inactivation (Zhao et al., 2008), and Kcnq1ot1 (Pandey et al., 2008) participating in repression of imprinted genes have all been implicated in Polycomb control. Actually, a significant part of the long interspersed non-coding RNAs (IncRNAs) in the human genome seems to be physically associated with PRC2 (Guttman and Rinn, 2012; Khalil et al., 2009). Control of PRC1 may also involve ncRNA (Yap et al., 2010). Recent work has also identified several shorter RNAs (50-200 nt) as candidate PRC2 regulators, which are transcribed from the $5^{\prime}$ end of PcG target genes (Kanhere et al., 2010). While HOTAIR works in trans (Gupta et al., 2010; Rinn et al., 2007), a large number of non-coding transcripts seem to act in cis (Figure 3.3). This type of silencing is likely to have widespread consequences, and ncRNAs can now be considered as PcG cofactors that could guide site-specific recruitment of PRC complexes to target genes.

RNA-mediated recruitment is especially attractive for PcG proteins due to the absence of specific DNA-binding components of most PRC complexes. Thus, PcG proteins must rely on other factors that can recognize specific DNA sequences. Drosophila biologists defined small stretches of DNA associated with target genes that are necessary and 

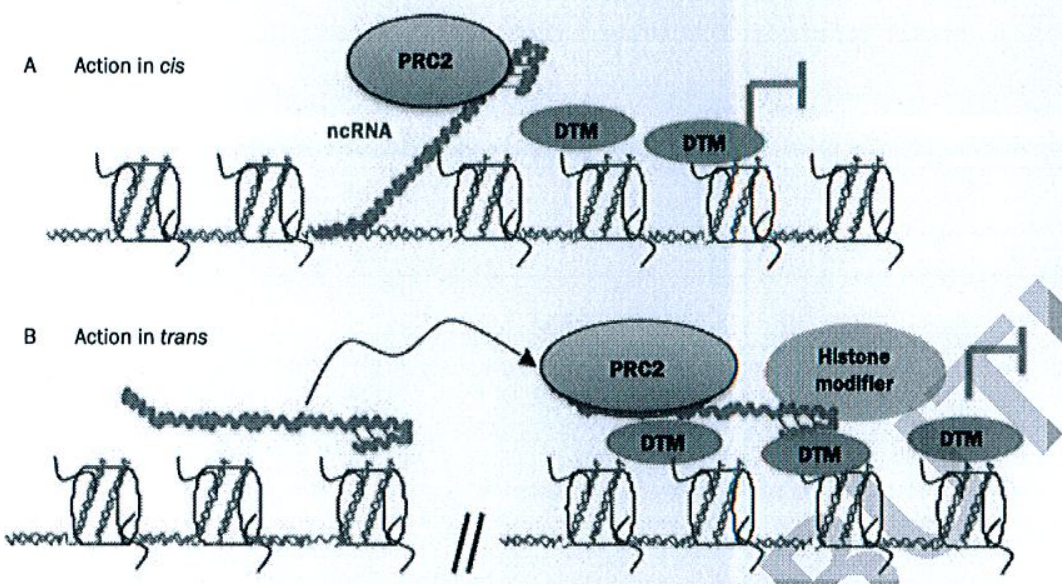

Figure 3.3

Models of ncRNA acting in cis (A) and trans (B) to recruit PRC2 complexes

sufficient to perform the silencing and maintenance tasks of the PcG system. These sequences have been called Polycomb-response elements (PREs). In flies, Polycomb complexes may contain sequence specific DNAbinding factors, such as Zeste, Pipsqueak (PSQ) or Polyhomeotic (Pho), to help bind PREs (Ringrose and Paro, 2004; Schwartz and Pirrotta, 2008). By contrast, mammalian and plant Polycomb complexes are not thought to contain such subunits (DNA binding proteins) or PREs, though a few PRE-like elements have recently been reported in mammals (Sing et al., 2009; Woo et al., 2010) and the JARID2 histone demethylase may facilitate binding (Li et al., 2010; Pasini et al., 2010; Peng et al., 2009). Therefore, the mechanism of PcG recruitment to thousands of genomic locations remains poorly understood. In this respect, ncRNAs may be playing a crucial role (Bracken and Helin, 2009; Guenther and Young, 2010). RNA-mediated recruitment represents an ideal mechanism for targeting chromatin modifiers in cis to specific alleles or unique locations in the genome, as they remain tethered to the site of transcription and can co-transcriptionally direct enzymatic activities to a unique region (Lee, 2009, 2010). They can also be complementary to genomic sequences and act in trans. Besides guiding functions allowing recruitment of chromatin complexes to specific genomic locations, ncRNAs can also act as scaffold elements to assemble large complexes in various processes (Guetg et al., 2012; Wang and Chang, 2011). A recent study has demonstrated a role of HOTAIR in scaffolding PCR 2 complex with H3K4 demethylase complex (Tsai et al., 2010). Furthermore, HOTAIR has been shown to interact 
with thousands of genomic loci, binding very short regions that serve as nucleation sites for PRC silencing (Chu et al., 2011).

To date there is a very limited number of examples of ncRNAs interacting with Polycomb complexes in plants (De Lucia and Dean, 2011; Kim and Sung, 2012; Muller and Goodrich, 2011). Non-coding RNAs have a central role in the regulation of FLOWERING LOCUS C (FLC), a transcriptional regulator that delays the transition to flowering. FLC expression is repressed by prolonged cold experienced during winter (Figure 3.2). This silencing is epigenetically stable and involves a Polycomblike mechanism and ncRNAs. The ncRNA COOLAIR is expressed from a promoter located in the $3^{\prime}$-flanking non-coding region of the FLC gene, it is partially spliced and it is involved in the early repression of FLC expression during vernalization (Swiezewski et al., 2009). By native RNA immunoprecipitation (RIP), the antisense COOLAIR transcript was found interacting with PRC2 (De Lucia et al., unpublished). As COOLAIR reaches its peak of expression, the amount of FLC mRNA starts to fall and transcription of COLDAIR is initiated (Heo and Sung, 2011). COLDAIR is a non-coding transcript that links decreased FLC expression to the maintenance of its repression by $\mathrm{PcG}$ protein complexes in $A$. thaliana. COLDAIR is encoded at the FLC locus as an intragenic sense RNA located in the first intron of the FLC gene. Its expression is increased by cold and it is reported to bind to CLF, the HMT subunit of plant PRC2 complex (Heo and Sung, 2011). However, Heo and Sung show that other proteins are required to ensure specificity of this RNA-protein interaction. Thus it appears that PRC2-IncRNA association is an evolutionarily conserved mechanism in PcG-mediated gene repression in eukaryotes. As for PRC1, a RNA binding protein interacts with LHP1, which may suggest some indirect implication of RNA in gene regulation by plant PRC1-like complex (Latrasse et al., 2011).

From all these data, it seems that non-coding RNAs are at the heart of developmental regulation, determining the epigenetic status and transcriptional network in any given cell type, and they provide a means to integrate external differentiation cues with dynamic nuclear responses.

\subsection{Emerging roles of PcG and ncRNAs in responses to environmental stress}

The Polycomb system is not only involved in the regulation of plant development. Recent studies show that cold-induced genes (Kwon et al., 
2009) and drought-stress response genes are regulated by PcG (Alexandre et al., 2009; Finnegan et al., 2011). Expression of the genes coding for Polycomb components in barley was found to be responsive to the abiotic stress-related hormone abscisic acid (ABA), implying an association with ABA-mediated processes during seed development and stress responses. Transcriptome analyses highlighted enrichment in stress response genes in lhp1 mutant (Latrasse et al., 2011).

Besides emerging evidence of a role of PcG proteins in response to environmental stress, ncRNAs may also play a critical role in the adaptation of developmental processes rather than in differentiation per se, as very few ncRNAs involved in development were previously revealed by classical genetic approaches. Like some miRNAs, certain ncRNAs are induced in various developmental processes as well as during abiotic stress responses in plants and animals (Jones-Rhoades et al., 2006; Prasanth and Spector, 2007; Sunkar et al., 2007; Yaish et al., 2011). In A. thaliana, Crespi's group identified ncRNAs displaying diverse regulation by environmental stimuli (Hirsch et al., 2006). A subsequent study based on genome-wide bioinformatic analysis identified 76 Arabidopsis noRNAs, among which a significant fraction have an altered aecumulation in response to abiotic stress (Ben Amor et al., 2009). For some of them the change in expression observed after salt treatment was maintained, while for others the induction was transient. Overexpression of two of these ncRNAs suggested that at least a subset of these newly identified ncRNAs have roles in developmental or stress adaptation programs. The number of examples of ncRNAs responding to stress conditions in plants is definitely increasing (Wu et al., 2012), suggesting that IncRNAs remain an underexplored class of ncRNAs that could be far more prevalent than previously appreciated to adapt growth and development to abiotic interactions. In animals, transcription of IncRNAs within gene regulation elements can modulate activity in response DNA damage (Hung et al., 2011). Hence, IncRNAs represent a class of factors that can be modulated by external stimuli.

\subsection{PcG protein functions in three- dimensional nuclear organization}

The eukaryotic genome is organized into functionally distinct segments, interspersed and intertwined, that undergo dynamic changes at different phases of the cell cycle and in response to various intracellular and extracellular signals. Furthermore, besides a compartmentalization of the 
From plant genomics to plant biotechnology

genome into chromosome territories, recent studies using chromosome conformation capture (3C) and derivative techniques have revealed a threedimensional folding of chromatin into functional globules (LiebermanAiden et al., 2009) and an important role of PcG proteins in higher levels of chromatin organization. The three-dimensional organization of Polycomb target genes in the cell nucleus has recently been revealed as an important parameter in their regulation in animals (for review see Bantignies and Cavalli, 2011; Delest et al., 2012). Long-distance interactions in cis or in trans (on different chromosomes) among the major elements bound by PcG proteins, including PREs and core promoters, have been visualized by microscopy-based techniques, $3 \mathrm{C}$ and derivative techniques (Comet et al., 2011; Sexton et al., 2012; Tolhuis et al., 2011). Importantly, these interactions change upon activation of a certain target gene, and they can be implicated in co-regulation of different target genes by $\mathrm{PCG}$ proteins via association in three-dimensional nuclear space (Bantignies et al., 2011). Thus, specific nuclear organization imposed by PcG proteins influences the maintenance of epigenetic states and regulates the co-repression of target genes. Among these kinds of contact, 'gene kissing' (between copies of a certain allele) also occurs in FLC silencing (De Lucia et al., unpublished), suggesting that they are a general mechanism of PcG regulation in eukaryotes. Thus, besides the classical linear epigenetic organization of the genome, the 3D nuclear architecture has to be taken into account to better understand the complex mechanisms that fine-tune the genetic element activities in various processes and in response to external stimuli.

\subsection{Perspectives: the role of Polycomb in abiotic and biotic stress response}

Stress puts cells at risk, and adaptation is crucial for maximizing cell survival. Cellular adaptation mechanisms include modification of certain aspects of cell physiology, such as the induction of efficient changes in gene expression programs by intracellular signalling networks. Recent studies using genome-wide approaches as well as single-cell transcription measurements, in combination with classical genetics, have shown that specific modulation of gene expression can be accomplished by several different strategies. How organisms can achieve generic and specific responses to different stresses by regulating gene expression at multiple stages of mRNA biogenesis, from chromatin structure to transcription, mRNA stability and translation, is nowadays a central question. 
In the light of the recent evidence concerning the involvement of the Polycomb system and ncRNAs in the abiotic stress response, the identification of Polycomb target genes and the Polycomb RNA partners under different stress conditions is an interesting area to explore. In addition, it has to be taken into account that changes in nuclear organization under stress conditions can allow coordinated co-regulation of a number of genes that need to be modulated in response to stress. Therefore, the recent progress in the identification of $\mathrm{a} 3 \mathrm{D}$ interactome for Polycomb target genes will be crucial for further investigation.

At the same time, the role of chromatin in the memory of the immune response is currently under intense investigation. Priming is a phenomenon that enables cells to respond more rapidly and/or sensitively during a second exposure to a stimulus than during the initial exposure. It is likely that a role of the Polycomb system will be revealed in the next future, in the light of the presence of $\mathrm{H} 3 \mathrm{~K} 27 \mathrm{me} 3$ at many defence-related genes in Arabidopsis, exploring a Polycomb-mediated chromatin memory for biotic stress responses.

\subsection{References}

Alexandre C, Moller-Steinbach Y, Schonrock N, Gruissem W, Hennig L (2009) Arabidopsis MSI1 Is Required for Negative Regulation of the Response to Drought Stress. Mol. Plant 2: 675-87.

Bantignies F, Cavalli G (2011) Polycomb group proteins: repression in 3D. Trends Genetics 27: 454-64.

Bantignies F, Roure V, Comet I, Leblanc B, Schuettengruber B, et al. (2011) Polycomb-dependent regulatory contacts between distant Hox loci in Drosophila. Cell 144: 214-26.

Bastow R, Mylne JS, Lister C, Lippman Z, Martienssen RA, et al. (2004) Vernalization requires epigenetic silencing of FLC by histone methylation. Nature 427: 164-7.

Beh LY, Colwell LJ, Francis NJ (2012) A core subunit of Polycomb repressive complex 1 is broadly conserved in function but not primary sequence. Proc. Natl. Acad. Sci. U.S.A. 109: E1063-71.

Ben Amor B, Wirth S, Merchan F, Laporte P, d'Aubenton-Carafa Y, et al. (2009) Novel long non-protein coding RNAs involved in Arabidopsis differentiation and stress responses. Genome Res. 19: 57-69.

Bracken AP, Helin K (2009) Polycomb group proteins: navigators of lineage pathways led astray in cancer. Nature Reviews Cancer 9: 773-84.

Bratzel F, Lopez-Torrejon G, Koch M, Del Pozo JC, Calonje M (2010) Keeping cell identity in arabidopsis requires PRC1 RING-finger homologs that catalyze H2A monoubiquitination. Curr. Biol. 20: 1853-9. 
Butenko Y, Ohad N (2011) Polycomb-group mediated epigenetic mechanisms through plant evolution. Biochim. Biophys. Acta 1809: 395-406.

Calonje M, Sanchez R, Chen L, Sung ZR (2008) EMBRYONIC FLOWER1 participates in polycomb group-mediated AG gene silencing in Arabidopsis. Plant Cell 20: 277-91.

Chanvivattana Y, Bishopp A, Schubert D, Stock C, Moon YH, et al. (2004) Interaction of Polycomb-group proteins controlling flowering in Arabidopsis. Development 131: 5263-76.

Chen D, Molitor A, Liu C, Shen WH (2010) The Arabidopsis PRC1-like ringfinger proteins are necessary for repression of embryonic traits during vegetative growth. Cell Res. 20: 1332-44.

Chu C, Qu K, Zhong FL, Artandi SE, Chang HY (2011) Genomic maps of long noncoding RNA occupancy reveal principles of RNA-chromatin interactions. Molecular Cell 44: 667-78.

Comet I, Schuettengruber B, Sexton T, Cavalli G (2011) A chromatin insulator driving three-dimensional Polycomb response element (PRE) contacts and Polycomb association with the chromatin fiber. Proc. Natl. Acad. Sci. U.S.A. 108: 2294-9.

Cui H, Benfey PN (2009) Interplay between SCARECROW, GA and LIKE HETEROCHROMATIN PROTEIN 1 in ground tissue patterning in the Arabidopsis root. Plant J. 58: 1016-27.

De Lucia F, Dean C (2011) Long non-coding RNAs and chromatin regulation. Curr. Opin. Plant Biol. 14: 168-73.

De Lucia F, Crevillen P, Jones AM, Greb T, Dean C (2008) A PHD-Polycomb Repressive Complex 2 triggers the epigenetic silencing of FLC during vernalization. Proc. Natl. Acad. Sci. U,S.A. 105: 16831-6.

del Olmo I, Lopez-Gonzalez L, Martin-Trillo MM, Martinez-Zapater JM, Pineiro M, et al. (2010) EARLY IN SHORT DAYS 7 (ESD7) encodes the catalytic subunit of DNA polymerase epsilon and is required for flowering repression through a mechanism involving epigenetic gene silencing. Plant J. 61: 623-36.

Delest A, Sexton T, Cavalli G(2012) Polycomb: a paradigm for genome organization from one to three dimensions. Curr. Opin. Cell Biol. 24: 405-14.

Endoh M, Endo TA, Endoh T, Isono K, Sharif J, et al. (2012) Histone H2A Mono-Ubiquitination Is a Crucial Step to Mediate PRC1-Dependent Repression of Developmental Genes to Maintain ES Cell Identity. PLoS Genetics 8: e1002774.

Eskeland R, Freyer E, Leeb M, Wutz A, Bickmore WA (2010) Histone acetylation and the maintenance of chromatin compaction by Polycomb repressive complexes. Cold Spring Harb Symp Quant Biol 75: 71-8.

Finnegan E, Bond DM, Buzas DM, Goodrich J, Helliwell CA, et al. (2011) Polycomb proteins regulate the quantitative induction of VERNALIZATION INSENSITIVE 3 in response to low temperatures. Plant J. 65: 382-91.

Gao Z, Zhang J, Bonasio R, Strino F, Sawai A, et al. (2012) PCGF homologs, CBX proteins, and RYBP define functionally distinct PRC1 family complexes. Molecular Cell 45: 344-56.

Gaudin V, Libault M, Pouteau S, Juul T, Zhao G, et al. (2001) Mutations in LIKE HETEROCHROMATIN PROTEIN 1 affect flowering time and plant architecture in Arabidopsis. Development 128: 4847-58. 
Gendall AR, Levy YY, Wilson A, Dean C (2001) The VERNALIZATION 2 gene mediates the epigenetic regulation of vernalization in Arabidopsis. Cell 107: 525-35.

Germann S, Gaudin V (2011) Mapping in vivo protein-DNA interactions in plants by DamID, a DNA adenine methylation-based method. In L Yuan, SE Perry, eds, Plant Transcription Factors: Methods and Protocols, Vol. 754, pp. 307-21. Springer Science Business Media, LLC, New York, USA.

Goodrich J, Puangsomlee P, Martin M, Long D, Meyerowitz EM, et al. (1997) A polycomb-group gene regulates homeotic gene expression in Arabidopsis. Nature 386: 44-51.

Greb T, Mylne JS, Crevillen P, Geraldo N, An H, et al. (2007) The PHD finger protein VRN5 functions in the epigenetic silencing of Arabidopsis FLC. Curr. Biol. 17: 73-8.

Grossniklaus U, Vielle-Calzada JP, Hoeppner MA, Gagliano WVB (1998) Maternal control of embryogenesis by MEDEA, a Polycomb groupgene in Arabidopsis. Science 280: 446-50.

Guenther MG, Young RA (2010) Transcription. Repressive transcription. Science 329: 150-1.

Guetg C, Scheifele F, Rosenthal F, Hottiger MO, Santoro R (2012) Inheritance of silent rDNA chromatin is mediated by PARP1 via noncoding RNA. Molecular Cell 45: 790-800.

Gupta RA, Shah N, Wang KC, Kim J, Horlings HM, et al. (2010) Long noncoding RNA HOTAIR reprograms chromatin state to promote cancer metastasis. Nature 464: 1071-6.

Guttman M, Rinn JL (2012) Modular regulatory principles of large non-coding RNAs. Nature 482: 339-46.

Hennig L, Derkacheva M (2009) Diversity of Polycomb group complexes in plants: same rules, different players? Trends Genet. 25: 414-23.

Hennig L, Taranto P, Walser M, Schonrock N, Gruissem W (2003) Arabidopsis MSI1 is required for eplgenetic maintenance of reproductive development. Development $130: 2555-65$.

Heo JB, Sung S (2011) Vernalization-mediated epigenetic silencing by a long intronic noncoding RNA. Science 331: 76-9.

Hirsch J. Lefort V, Vankersschaver M, Boualem A, Lucas A, et al. (2006) Characterization of 43 non-protein-coding mRNA genes in Arabidopsis, including the MIR162a-derived transcripts. Plant Physiol. 140: 1192-204.

Holec S, Berger F (2012) Polycomb group complexes mediate developmental transitions in plants. Plant Physiol. 158: 35-43.

Hung T, Wang Y, Lin MF, Koegel AK, Kotake Y, et al. (2011) Extensive and coordinated transcription of noncoding RNAs within cell-cycle promoters. Nat. Genet. 43: 621-9.

Jones-Rhoades MW, Bartel DP, Bartel B (2006) MicroRNAs and their regulatory roles in plants. Annu. Rev. Plant Biol. 57: 19-53.

Kanhere A, Viiri K, Araujo CC, Rasaiyaah J, Bouwman RD, et al. (2010) Short RNAs are transcribed from repressed polycomb target genes and interact with polycomb repressive complex-2. Mol. Cell 38: 675-88. 
Khalil AM, Guttman M, Huarte M, Garber M, Raj A, et al. (2009) Many human large intergenic noncoding RNAs associate with chromatin-modifying complexes and affect gene expression. Proc. Natl. Acad. Sci. U.S.A. 106: 11667-72.

Kim DH, Doyle MR, Sung S, Amasino RM (2009) Vernalization: winter and the timing of flowering in plants. Annu. Rev. Cell Dev. Biol. 25: 277-99.

Kim ED, Sung S (2012) Long noncoding RNA: unveiling hidden layer of gene regulatory networks. Trends Plant Sci. 17: 16-21.

Köhler C, Hennig L (2010) Regulation of cell identity by plant Polycomb and trithorax group proteins. Curr. Opin. Genet. Dev. 20: 541-7.

Kwon CS, Lee D, Choi G, Chung WI (2009) Histone occupancy-dependent and -independent removal of H3K27 trimethylation at cold-responsive genes in Arabidopsis. Plant J. 60: 112-21.

Lafos M, Kroll P, Hohenstatt ML, Thorpe FL, Clarenz O, et al. (2011) Dynamic regulation of $\mathrm{H} 3 \mathrm{~K} 27$ trimethylation during Arabidopsis differentiation. PLoS Genet. 7: e1002040.

Lagarou A, Mohd-Sarip A, Moshkin YM, Chalkley GE, Bezstarosti K, et al. (2008) dKDM2 couples histone H2A ubiquitylation to histone H3 demethylation during Polycomb group silencing. Genes Dev. 22: 2799-810.

Landeira D, Fisher AG (2011) Inactive yet indispensable: the tale of Jarid2. Trends Cell Biol. 21: 74-80.

Latrasse D, Germann S, Houba-Herin N, Dubois E, Bui-Prodhomme D, et al. (2011) Control of flowering and cell fate by LIF2, an RNA binding partner of the polycomb complex component LHP1. PLoS One 6: e16592.

Lee JT (2009) Lessons from X-chromosome inactivation: long ncRNA as guides and tethers to the epigenome. Genes Dev. 23: 1831-42.

Lee JT (2010) The X as model for RNA's niche in epigenomic regulation. Cold Spring Harb. Perspect. Biol. 2: a003749.

Lehmann L, Ferrari R, Vashisht AA, Wohlschlegel JA, Kurdistani SK, et al. (2012) Polycomb Repressive Complex 1 (PRC1) disassembles RNA Polymerase II Preinitiation Complexes, J. Biol. Chem. 287: 35784-94.

Li G, Margueron R, Ku M, Chambon P, Bernstein BE, et al. (2010) Jarid2 and PRC2, partners in regulating gene expression. Genes Dev. 24: 368-80.

Li H, Luan S (2011) The cyclophilin AtCYP71 interacts with CAF-1 and LHP1 and functions in multiple chromatin remodeling processes. Mol. Plant 4: 748-58.

Libault M, Tessadori F, Germann S, Snijder B, Fransz F, et al. (2005) The Arabidopsis LHP1 protein is a component of euchromatin. Planta 222: 910-25.

Lieberman-Aiden E, van Berkum NL, Williams L, Imakaev M, Ragoczy T, et al. (2009) Comprehensive mapping of long-range interactions reveals folding principles of the human genome. Science 326: 289-93.

Liu C, Xi W, Shen L, Tan C, Yu H (2009) Regulation of floral patterning by flowering time genes. Dev. Cell 16: 711-22.

Lo SM, Follmer NE, Lengsfeld BM, Madamba EV, Seong S, et al. (2012) A Bridging Model for Persistence of a Polycomb Group Protein Complex through DNA Replication In Vitro. Molecular Cell 46: 784-96.

Luo M, Bilodeau P, Koltunow A, Dennis ES, Peacock WJ, et al. (1999) Genes controlling fertilization-independent seed development in Arabidopsis thaliana. Proc. Natl. Acad. Sci. U.S.A. 96: 296-301. 
Margueron R, Reinberg D (2011) The Polycomb complex PRC2 and its mark in life. Nature 469: 343-9.

Meyerowitz EM (2002) Plants compared to animals: the broadest comparative study of development. Science 295: 1482-5.

Muller R, Goodrich J (2011) Sweet memories: epigenetic control in flowering. F1000 Biol. Rep. 3: 13.

Mylne JS, Barrett L, Tessadori F, Mesnage S, Johnson L, et al. (2006) LHP1, the Arabidopsis homologue of Heterochromatin Protein1, is required for epigenetic silencing of FLC. Proc. Natl. Acad. Sci. U.S.A. 103: 5012-17.

Nagano T, Fraser P (2011) No-nonsense functions for long noncoding RNAs. Cell 145: 178-81.

Ohad N, Yadegari R, Margossian L, Hannon M, Michaeli D, et al. (1999) Mutations in FIE, a WD polycomb group gene, allow endosperm development without fertilization. Plant Cell 11: 407-15.

Pandey RR, Mondal T, Mohammad F, Enroth S, Redrup L, et al. (2008) Kenq1ot1 antisense noncoding RNA mediates lineage-specific transcriptional silencing through chromatin-level regulation. Mol. Cell 32: 232-46.

Pasini D, Cloos PA, Walfridsson J, Olsson L, Bukowski JP, et al. (2010) JARID2 regulates binding of the Polycomb repressive complex 2 to target genes in ES cells. Nature 464: 306-10.

Peng JC, Valouev A, Swigut T, Zhang J, Zhao Y, et ą. (2009) Jarid2/Jumonji coordinates control of PRC2 enzymatic activity and target gene occupancy in pluripotent cells. Cell 139: 1290-302.

Prasanth KV, Spector DL (2007) Eukaryotic regulatory RNAs: an answer to the 'genome complexity' conundrum. Genes Dev. 21: 11-42.

Ringrose L, Paro R (2004) Epigenetic regulation of cellular memory by the Polycomb and Trithorax group proteins. Annu. Rev. Genet. 38: 413-43.

Rinn JL, Kertesz M, Wang JK, Squazzo SL, Xu X, et al. (2007) Functional demarcation of active and silent chromatin domains in human HOX loci by noncoding RNÁs. Cell 129: 1311-23.

Sanchez-Pulido L, Devos D, Sung ZR, Calonje M (2008) RAWUL: a new ubiquitin-like domain in PRC1 ring finger proteins that unveils putative plant and worm PRC1 orthologs. BMC Genomics 9: 308.

Schuetfengruber B, Cavalli G (2009) Recruitment of polycomb group complexes and their role in the dynamic regulation of cell fate choice. Development 136: $3531-42$.

Schwartz YB, Pirrotta V (2008) Polycomb complexes and epigenetic states. Curr. Opin. Cell Biol. 20: 266-73.

Sexton T, Yaffe E, Kenigsberg E, Bantignies F, Leblanc B, et al. (2012) Threedimensional folding and functional organization principles of the Drosophila genome. Cell 148: 458-72.

Simon JA, Kingston RE (2009) Mechanisms of polycomb gene silencing: knowns and unknowns. Nat. Rev. Mol. Cell Biol. 10: 697-708.

Sing A, Pannell D, Karaiskakis A, Sturgeon K, Djabali M, et al. (2009) A vertebrate Polycomb response element governs segmentation of the posterior hindbrain. Cell 138: 885-97.

Spitale RC, Tsai MC, Chang HY (2011) RNA templating the epigenome: long noncoding RNAs as molecular scaffolds. Epigenetics 6: 539-43. 
Sunkar R, Chinnusamy V, Zhu J, Zhu JK (2007) Small RNAs as big players in plant abiotic stress responses and nutrient deprivation. Trends Plant Sci. 12: 301-9.

Swiezewski S, Liu F, Magusin A, Dean C (2009) Cold-induced silencing by long antisense transcripts of an Arabidopsis Polycomb target. Nature 462: 799-802.

Tavares L, Dimitrova E, Oxley D, Webster J, Poot R, et al. (2012) RYBP-PRC1 complexes mediate $\mathrm{H} 2 \mathrm{~A}$ ubiquitylation at polycomb target sites independently of PRC2 and H3K27me3. Cell 148: 664-78.

Tolhuis B, Blom M, Kerkhoven RM, Pagie L, Teunissen H, et al. (2011) Interactions among Polycomb domains are guided by chromosome architecture. PLoS Genet. 7: e1001343.

Tsai MC, Manor O, Wan Y, Mosammaparast N, Wang JK, et al. (2010) Long noncoding RNA as modular scaffold of histone modification complexes. Science 329: 689-93.

Turck F, Roudier F, Farrona S, Martin-Magniette ML, Guillaume E, et al. (2007) Arabidopsis TFL2/LHP1 specifically associates with genes marked by trimethylation of histone $\mathrm{H} 3$ lysine 27. PLoS Genet. 3: e86.

Wang KC, Chang HY (2011) Molecular mechanisms of long noncoding RNAs. Molecular Cell 43: 904-14.

Woo CJ, Kharchenko PV, Daheron L, Park PJ, Kingston RE (2010) A region of the human HOXD cluster that confers polycomb-group responsiveness. Cell 140: 99-110.

Wu J, Okada T, Fukushima T, Tsudzuki T, Sugiura M, et al. (2012) A novel hypoxic stress-responsive long non-coding RNA transcribed by RNA polymerase III in Arabidopsis. RNA Biology 9: 302-13.

Xu L, Shen WH (2008) Polycomb silencing of KNOX genes confines shoot stem cell niches in Arabidopsis, Curr. Biol. 18: 1966-71.

Yaish MW, Colasanti J, Rothstein SJ (2011) The role of epigenetic processes in controlling flowering time in plants exposed to stress. J. Exp. Botany 62: 3727-35.

Yap KL, Li S, Munoz-Cabello AM, Raguz S, Zeng L, et al. (2010) Molecular interplay of the noncoding RNA ANRIL and methylated histone H3 lysine 27 by polycomb CBX7 in transcriptional silencing of INK4a. Mol. Cell 38: $662-74$.

Yu M, Mazor T, Huang H, Huang HT, Kathrein KL, et al. (2012) Direct recruitment of polycomb repressive complex 1 to chromatin by core binding transcription factors. Mol. Cell 45: 330-43.

Zhang X, Clarenz O, Cokus S, Bernatavichute YV, Pellegrini M, et al. (2007a) Whole-genome analysis of histone $\mathrm{H} 3$ lysine 27 trimethylation in Arabidopsis. PLoS Biol. 5: e129.

Zhang X, Germann S, Blus BJ, Khorasanizadeh S, Gaudin V, et al. (2007b) The Arabidopsis LHP1 protein colocalizes with histone H3 Lys27 trimethylation. Nat. Struct. Mol. Biol. 14: 869-71.

Zhao J, Sun BK, Erwin JA, Song JJ, Lee JT (2008) Polycomb proteins targeted by a short repeat RNA to the mouse X chromosome. Science 322: 750-6. 